\title{
Surtos epidêmicos de dermatite causada por mariposas do gênero Hylesia (Lepidóptera: Hemileucidae) no Estado de São Paulo, Brasil
}

\author{
Epidemic outbreaks of dermatitis caused by Hylesia (Lepidoptera: Hemileucidae), \\ in S. Paulo State, Brazil
}

Carmen Moreno Glasser*, João Luiz Cardoso**, Glória Cristina Carréri-Bruno*, Maria de Fátima Domingos*, Roberto Henrique Pinto Moraes*", Ricardo Mário de Carvalho Ciaravolo*

\begin{abstract}
GLASSER, C.M. et al. Surtos epidêmicos de dermatite causada por mariposas do gĉnero Hylesia (Lepidóptera: Hemileucidae) no Estado de São Paulo, Brasil. Rev. Saúde Pública, 27: 217-20, 1993. Surtos epidêmicos de dermatite causada por Hylesia sp foram assinalados no litoral do Estado de São Paulo, no período de dezembro de 1989 a dezembro de 1991. O fenômeno assumiu sua maior intensidade em Bertioga, Município de Santos, onde foram registrados 612 casos. Foram atingidos outros 12 municípios da região, estimando-se que algumas centenas de casos procuraram os serviços de saúde locais. Na maioria dos casos verificou-se lesões eritemato-pápulo-pruriginosas, que regrediram em média de 7 a 14 dias. Para tratamento foram utilizados anti-histamímicos sistêmicos corticosteróides tópicos e compressas frias. Ocorreram três episódios epidêmicos no período citado, todos eles coincidindo com o início da estação chuvosa (novembro a janeiro). A cada episódio verificou-se um deslocamento do fenômeno no sentido Norte-Sul. A principal medida profilática utilizada foi a divulgação, junto à população, das medidas de redução de exposição ao agente. Para prédios com elevada infestação por mariposas, foi estudada a efetividade da aplicação de inseticida residual, como medida de redução dos níveis de infestação por mariposas. Obteve-se resultados satisfatórios com deltametrina ra dose de $50 \mathrm{mg} / \mathrm{m}^{2}$ de parede.
\end{abstract}

Descrilores: Dermatite de contato, prevenção. Mariposas, patogenicidade.

\section{Introduçáo}

O lepidopterismo por Hylesia sp tem se restringido principalmente ao continente Sul-Americano, sendo pouca as publicaçð̄es sobre observaçōes acerca do fenômeno.

Casos de dermatite causados por adultos de $\mathrm{Hy}$ lesia sp já foram assinalados na Guiana France$\mathrm{sa}^{2,10,13}$, Argentina $4,8,9$, Peru$^{1}$, e no México ${ }^{14}$. No Brasil, adultos desse gênero foram apontados por Gusmão e col. ${ }^{6}$ como responsáveis por surto epidêmico com centenas de casos de dermatite, ocorrido em maio de 1960, em Serra do Navio, Amapá. Em 1980, Mascarenhas e col. ${ }^{12}$ notificaram a ocorrência de um novo surto epidêmico, desta vez em Montes Claros, Minas Gcrais.

\footnotetext{
* Superintendência de Controle de Endemias (SUCEN) São Paulo, SP - Brasil

* Instituto Butanta - São Paulo, SP - Brasil
}

Separatas/Reprints: C.M. Glasser - Rua Paula Souza, 166 01027-000 - São Paulo, SP - Brasil

Edição subvencionada pela FAPESP. Processo Medicina 93/ 0208-5.
No período de dezembro de 1989 a dezembro de 1991 registraram-se surtos de dermatite, associados à presença abundante de mariposas Hylesia, em 13 municípios do litoral do Estado de São Paulo.

Da mesma maneira que em episódios registrados em outros locais das Américas, os surtos verificados no litoral paulista tiveram ocorrência sazonal e curta duração6,7,14. Mesmo assim, a adoção de medidas profiláticas foi dc grande importância devido ao clcvado númcro de pessoas acometidas pela dermatite nos períodos cpidêmi$\cos$ e à sintomatologia intensa apresentada por parte dos casos.

É objetivo do presente trabalho relatar as observações feitas acerca dos episódios ocorridos nessa rcgião paulista, e apresentar as medidas profiláticas adotadas.

\section{Descoberta do primeiro surto epidémico e descriçáo dos novos episódios}

Em meados de dezembro de 1989 teve afluxo às Unidades de Saúde do Distrito de Bertioga, Município de Santos, casos de dermatite em número muito elevado. A presença nesse mesmo período, 
de grande número de mariposas, levou as autoridades sanitárias locais a levantarem a hipótese de serem estas as causadoras do problema. Exemplares de mariposas foram capturados e identificados como Hylesia paulex, Dogniu, 1922*. O surto epidêmico teve uma duração de aproximadamente 30 dias com pico na última semana de 1989 , chegando a um total de 612 casos registrados, referentes a veranistas e população residente ${ }^{3}$.

Como fatores agravantes do episódio, podemos citar o intenso afluxo de veranistas na área; a extensa área do corpo, livre de vestimentas, além da permanência das pessoas em locais abertos e iluminados durante o período crepuscular vespertino, quando as mariposas estão em intensa atividade de vôo ${ }^{6}$.

Nesse período (dezembro/89 e janeiro/91), ainda na Baixada Santista, foram registrados surtos de dermatite causados por Hylesia sp, com dezenas de casos nos municípios de Itanhaém e Peruíbe (Figura).
Houve dificuldades para se determinar o número de pessoas afetadas nos diversos municípios e períodos em função da doença não ser de notificação compulsória e de parte dos casos não procurar assistência médica, por apresentar sintomatologia branda. As Unidades de Saúde de Bertioga foram as únicas a organizarem um sistema de registro diário dos casos de dermatite atendidos. Optou-se então por fazer uma avaliação da intensidade do fenômeno, utilizando a estimativa feita pelos Serviços de Saúde sobre o número de casos por eles atendidos, acrescidos do número de casos diretamente informados à SUCEN, pela população, quando da notificação de locais com elevada infestação de mariposas. Com esses valores estimados, agruparam-se os municipios em três intervalos quanto à ocorrência de casos, conforme Figura.

O período de ocorrência dos três episódios epidêmicos, evidencia a existência de um único período anual de abundância de mariposas do cita-

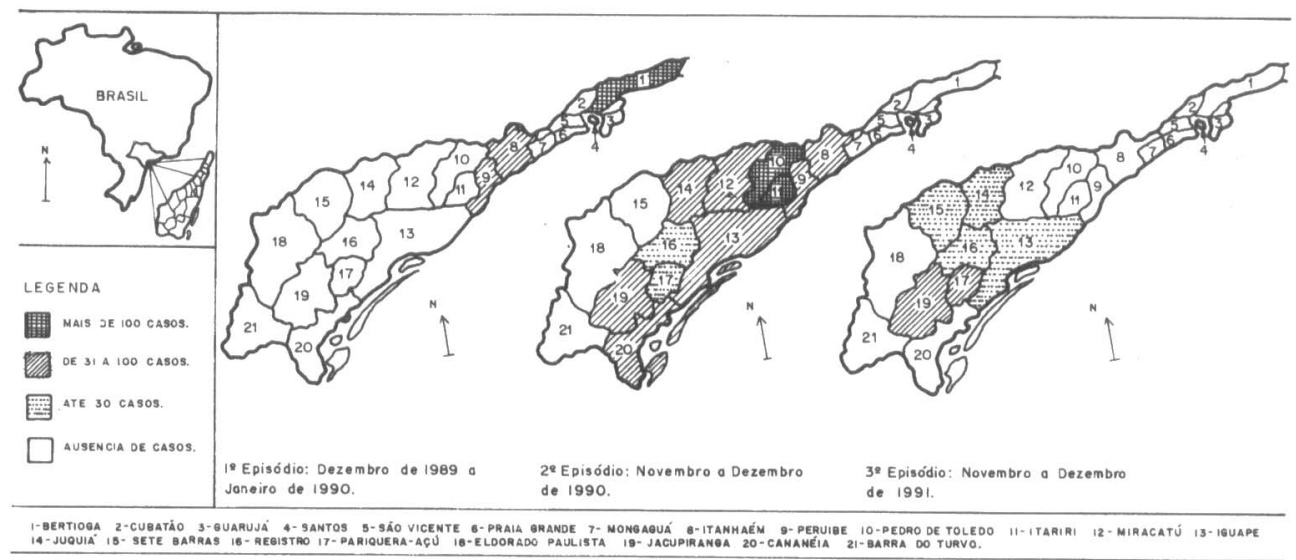

Fonte - Unidades Sanitárias Municipais e SUCEN.

Figura 1. Ocorrência de dermatite causada por Hylesia sp, segundo município, período e estimativa de casos. Litoral do Estado de São Paulo, 1989 a 1991.

O fenômeno voltou a ser observado a partir da segunda quinzena de novembro/1990. Dessa vez, reincidindo nos municípios de Itanhaém e Peruíbe e manifestando-se pela primeira vez em 9 municípios do Vale do Ribeira (Figura). Nesses municípios, apesar da ocorrência de casos ser maior na zona urbana, houve também registro de casos na zona rural.

Em novembro de 1991, o fenômeno foi novamente observado, restringindo-se este terceiro episódio ao Município do Vale do Ribeira ${ }^{5}$, e manifestando-se com menor intensidade (Figura).

* Comunicaçãopessoal (1990) de C. Lemaire (Gordes, France). do gênero, para as condições climáticas do litoral paulista, coincidindo com o início da estação chuvosa (novembro a janeiro). Por outro lado, verificou-se um deslocamento geográfico do fenômeno no sentido Norte-Sul a cada surto ocorrido, conforme mostra a Figura.

Outras características observadas de maneira constante nos três episódios ocorridos, foram: presença importante de cobertura vegetal nas áreas urbanas atingidas, além da proximidade com a Mata Atlântica representada pela floresta perenifólia higrófila que cobre o sistema Serra do Mar; a atividade das mariposas apresentou-se com maior intensidade no crepúsculo vespertino; as mariposas, apesar de estarem presentes na maioria 
das residências das áreas infestadas, mostraram preferência por prédios permanentemente iluminados e com paredes claras; a duração dos episódios situou-se em torno de $\mathbf{3 0}$ dias para os diversos 10cais atingidos; a grande maioria dos casos de dermatite ocorreu em função do contato com as "flechas venenosas"11 liberadas pelas mariposas durante seu vôo em tomo de focos de luz, e não pelo contato direto com as mesmas.

\section{Quadro clínico}

Na maioria dos casos, lesð̄es eritemato-pápulopruriginosas acometendo áreas expostas do tegumento foram observadas em pessoas que tiveram contato com o agente. $O$ quadro dermatológico instalou-se nas primeiras 24 h após a exposição, iniciando-se por prurido e eritema. As lesões evoluíram para pápulas intensamente pruriginosas. $O$ quadro, cuja duraçāo média foi de 7 a 14 dias, regrediu sem lesőes residuais.

No tratamento, foram utilizados antihistamínicos sistêmicos, corticosteróides tópicos e compressas frias.

\section{Medidas proflláticas adotadas}

A partir da descoberta de que o surto de dermatite que atingia Bertioga era causado por mariposas, iniciou-se a divulgação de medidas para redução da exposição da população a esses insetos e às "flechas" por eles liberadas. Para isso, utilizou-se de meios de comunicação de massa (rádio e jomal), contatos com lideranças locais, fixação de cartazes em serviços de saúde alertando para o problema e distribuição de folhetos contendo orientaçōes para os usuários desses serviços. Foram também visitadas as farmácias, para divulgação do fenômeno e solicitação de encaminhamento de pessoas afetadas pela dermatite às Unidades de Saúde. As orientaçőes passadas à população, pelos citados meios de comunicação, basearam-se nas observações iniciais sobre o surto e em informaçōes assinaladas por Gusmão e col. ${ }^{6}$ sobre diversos aspectos do comportamento de mariposas do gênero Hylesia, sobre a facilidade com que as "flechas" causadoras de dermatite se destacam do corpo desses lepidópteros, depositando-se nos móveis, lençóis, outros objetos e na própria pele, e sobre algumas medidas profiláticas adotadas em outras áreas, durante episódios semelhantes.

As recomendaç̃̃es consistiram em medidas que evitassem ou reduzissem o contato da população com as mariposas e "flechas" por elas liberadas, além de orientação, aos pacientes, para procurarem o Serviço de Saúde adequado.

As atividades de divulgação foram estendidas a todos os municípios atingidos pela fenômeno. Verificou-se, no entanto, que embora essas atividades fossem de fundamental importância para 0 controle da exposiçāo humana, existiam situações em que elas pouco contribuíam para a redução da exposição. Isso ocorria em locais externos em que a concentração de mariposas era muito elevada, desde algumas mariposas pousadas por metro quadrado de parede até algumas dezenas. Prédios com esses niveis de infestação apresentavam algumas características comuns: permaneciam iluminados durante toda a noite e tinham as paredes claras (Serviços de Saúde, Delegacias de Polícia, Escolas, Praças Públicas, outros Orgãos Públicos...). A quantidade de mariposas pousadas nas paredes externas desses prédios era sempre muito superior ao número desses lepidópteros que conseguiam invadir o seu interior, pois medidas para dificultar a sua entrada estavam sendo postas em prática.

Em função dessas observaçð̃es, considerou-se de interesse estudar a viabilidade do tratamento das paredes externas de prédios altamente infestados, com inseticidas de ação residual. Foram realizado testes utilizando deltametrina na formulação suspensão concentrada, nas doses de 25 e $50 \mathrm{mg}$ de ingredientes ativo $\left(\mathrm{i} / \mathrm{m}^{2}\right)$ de parede. Apenas para a dose de $50 \mathrm{mg} \mathrm{i} / \mathrm{m}^{2}$ de parede obtiveram-se resultados satisfatórios, que foram os seguintes:

- As mariposas atingidas diretamente pelo inseticida borrifado morreram a aproximadamente $10 \mathrm{~min}$. após a aplicação. Nesse pequeno período voaram pouco, não representando um agravante para a exposição do desinsetizador e de pessoas que circulavam próximo ao local tratado. Os equipamentos de proteção individual usados pelo desinsetizador foram os mesmos indicados para borrifação de paredes (capacete, avental de manga comprida, máscara, óculos, luvas e botas) e se mostraram suficientes para evitar o surgimento de dermatite;

- Foi possível avaliar que a ação residual do inseticida aplicado permaneceu em níveis adequados até 3 semanas após o tratamento. Verificou-se, diariamente, grande mortalidade de mariposas encontradas próximas às paredes borrifadas, sendo raros os exemplares vivos pousados nessas paredes durante o dia. $O$ número de mariposas mortas foi diminuindo gradativamente, sendo que na quarta semana elas praticamente desapareceram, impossibilitando a continuidade da avaliação. 
Esse tratamento, além de reduzir a exposição das pessoas que trabalham ou frequientam locais altamente atrativos a esses insetos, deve também diminuir a exposição daquelas que habitam as casas da proximidade.

\section{Agradecimentos}

Às equipes-técnicas das Unidades Sanitárias dos 13 municípios onde ocorreram surtos epidêmicos, pelas informações fornecidas acerca tos casos de dermatite atendidos; ao Dr. Claude Lemaire do Museu Nacional de História Natural - Paris, pela identificação da espécie de Hylesia.

GLASSER, C. M. et al. [Epidemic outbreaks of dermatitis caused by Hylesia (Lepidoptera: Hemileucidae), in S. Paulo State, Brazill]. Rev. Saúde Pública, 27: 217-20, 1993. Epidemic outbreaks of dermatitis caused by Hylesia sp wich occurred in the coastal region of the State of S. Paulo during the period of December 1989 to December 1991 are confirmed. The incident assumed its greatest intensity in Bertioga, in Santos County, where 612 cases were registered. The outbreak also affected 12 other counties in that region and it was estimated that hundred of affected persons sought the Local Health Service Care. The majority presented with erythematous and prutiginous lesions and papula which lasted 7 to 14 days on average. Treatment consisted of systemic administration of antihistamines, and the use of topic corticosteroides and cold compresses. During the abovementioned period, three epidemic episodes, coninciding with the rainy season (November to January), ocurred. They were first observed in the northem part of the coastal area and then spread to the south. Information as to how avoid contact with the moth was the main prophylactic measure. In highly infested buildings the effectiveness of residual insecticide procedure was used in the attempt to reduce the level of moth infestation. Satisfatory results were obtained with deltametrin applied in a dosage of $50 \mathrm{mg} / \mathrm{m}^{2}$ of wall.

Keywords: Dermatitis, contact, prevention. Moths, patogenicity.

\section{Referências Bibliográflcas}

1. ALLARD, H.F. \& ALLARD, H.A. Venomous moths and butterflies. J. Washington Acad. Sci., 48: 18-51, 1958.

2. BOYE, R. La papillonite guyanaise. Bull. Soc. Pathol. Éxot., 25: 1099-107, 1932.

3. CARDOSO, J.L.C.; B. FILIIO, T.S.; CARNEIRO, E.C.G.; MORAES, H.P. Surto de dermatite por Hylesia paulex no litoral do Estado de São Paulo, Bertioga, verão de 1990. In: Simpósio da Sociedade Brasileira de Toxicologia, 12. São Paulo, 1990.

4. DALLAS, E.D. Otro caso de dermitis extendida, producida por un lepidóptero y notas sobre Hylesia nigricans Berg (Lep. Bombicidade). In: Reunion de la Sociedad Argentina de Patologia Regional del Norte, 82, Jujuy, 1993. Anais. Buenos Aires. Universidad de Buenos Aires, s.d. p. 469-74.

5. DOMINGOS, M.F.; CARDOSO, J.C.C.; VALDERRAMA, R.H. Hylesia sp no litoral sul de São Paulo: relato do terceiro surto. Rev. Soc. Bras. Med. Trop, 25: Supl, $110,1992$.

6. GUSMÃ̃, H.H.; FORATTINI, O.P. \& ROETBERG, A. Dermatite provocada por lepidópteros do gênero Hylesia. Rev. Inst. Med. Trop. S. Paulo, 3: 1194-120, 1961.

7. HARWOOD, R.F.; JAMES, M.T. Entomology in human and animal health. 7 ed. New York, MacMillan Publ. 1979.

8. JORG, M.E. Nota previa sobre el princípio activo urtigante de Hylesia nigricans (Lepidóptera, Hemileucidae) y las dermitis provocadas por el mismo. In: Reunion Sociedad Argentina de Patologia Regional del Norte, $8^{2}$, Jujuy, 1993. Anais. Buenos Aires. Universidad de Buenos Aires, s.d. p. 482-95.

9. JORG, M. E. Dematosis lepidopterianas (Segunda nota) In: Reunion Sociedad Argentina de Patologia Regional del Norte, 9", Mendonza, 1935 Anais. Jujuy, Universidad de Buenos Aires, 1939. V. 3, p. 1617-35.

10. LEGER, M. \& MOUZELS, P. Dermatoses prurigineuse determinée par des Pappilons satumidae du genre Hylesia. Bull. Soc. Pathol. Exol., 11: 104-7, 1918.

11. LAMY, M. \& L.EMAIRE, C. Contribution à la systématique des Hylesia: étude au microscope electronique à balayage des "flechettes" unicantcs. Bull. Soc. Entomol. France, 88: 176-92, 1983.

12. MASCARENHAS, C.S.; VULCANO, M.A.; PEREIRA, F.S. Nova constatação de dermatite provocada por lepidópteros do gênero Hylesia Hubner. Lundiana(1): 143 $8,1980$.

13. TISSEUIL, J. Contribution a l'étude de la papillonite guyanaise. Bull Soc. Pathol. Exot., 28: 719-21, 1935.

14. VILLANUEVA, A. et al. Moth associated dematitescozumel, México. MMWR, 39(13): 219-20, 1990.

Recebido para publicação em 4.1 .1993 Aprovado para publicação em 1.4.1993 